\title{
AGOSTINHO FRENTE AOS CÉTICOS ACADÊMICOS
}

\author{
Mariana Paolozzi
}

Universidade Federal de Santa Catarina

\begin{abstract}
Resumo: Este artigo ressalta alguns aspectos da crítica agostiniana aos céticos acadêmicos. Tentando demonstrar que é possível alcançar a verdade, Agostinho discute um dos grandes problemas da filosofia, o do conhecimento e da certeza. Ele aborda esse tema principal a partir da interrogação dos filósofos acadêmicos: a filosofia consiste somente na "busca" (investigatio), talvez vã, ou consiste na "descoberta" (inventio) da verdade? Será feita uma análise do diálogo agostiniano Contra Academicos a partir de seu pano de fundo, que nos situa no horizonte da filosofia dos acatalépticos (acadêmicos) e do materialismo, tanto estóico quanto epicurista. $O$ desafio de Agostinho será o de suplantar não apenas os acadêmicos, mas deverá fazê-lo sem afirmar o materialismo estoico (e muito menos o epicurista). As obras posteriores de Agostinho que abarcam esse tema desenvolvem os principais argumentos desse diálogo da juventude que, portanto, pode ser considerado a principal fonte a respeito do assunto.
\end{abstract}

Palavras-chave: Agostinho; ceticismo; Nova Academia; verdade.

\begin{abstract}
This article examines Augustine's criticisms toward the academic skeptics. To demonstrate that truth can be an achievable aim, he addresses the recurring philosophical issues of knowledge and certainty by focusing on the academic philosophers' question of whether philosophy is just the, perhaps vain, "quest" (investigatio) for the truth or, alternatively, is the "discovery" (inventio) of the truth. We carry out an analysis of the Augustinian dialogue Contra Academicos that emphasizes the philosophical context where it is grounded - the acataleptic (academic) philosophy and either the stoic or Epicurean materialism. Augustine's main challenge lay in overcoming the academics without embracing the stoic, and a fortiori the Epicurean, materialism. In later works, Augustine revisits and digs deeper into the main arguments he had put forward in this dialogue, reason for which Contra Academicos is key to understand his view on knowledge and truth.
\end{abstract}

Keywords: Augustine; skepticism; New Academy; truth.

\section{Introdução}

Aos 19 anos, a leitura do Hortêncio, de Cícero, impulsionou Agostinho em busca da verdade. Nesse caminho, durante nove anos foi maniqueísta, e, em seguida, cético: aderindo às posições da "Nova Academia", desistiu, por isso, de conhecer a verdade.

Parte da sua trajetória intelectual, de seu sinuoso e intenso percurso, pode ser acompanhada na leitura das Confissões (ver, por exemplo V, X-19). Sua conversão ao cristianismo, aos 32 anos, provocou uma reviravolta de $180^{\circ}$. Empenhou-se então, em novembro de 386, em refutar o ceticismo ciceroniano, espelhado na doutrina da Nova Academia. A redação dessa obra - 
intitulada Contra Academicos - foi interrompida para que compusesse o De beata vita e também o De ordine (v. Retractationes I, II, 2; I, III, 1).

Tentando demonstrar, aí, que é possível alcançar a verdade, Agostinho discute um dos grandes problemas da filosofia, o do conhecimento e da certeza. Aborda esse tema principal na perspectiva dos filósofos da Nova Academia: a filosofia consiste somente na "busca" (investigatio), talvez vã, ou consiste na "descoberta" (inventio) da verdade?

Quando fala dos acadêmicos, nessa obra, Agostinho refere-se a Cícero (106-43 a.C.) e às raízes da sua doutrina, introduzidas no mundo romano por alguns pensadores gregos (destacando-se dentre eles Arcesilau e Carnéades). As obras de Cícero são indicadas como contendo o conjunto dos argumentos acadêmicos, e é ele claramente quem Agostinho pretendeu refutar $^{1}$, sendo a sua principal e exclusiva fonte de referência ${ }^{2}$.

Não foi difícil, para Agostinho, reproduzir o sistema probabilista de Cícero: era o mesmo a que aderiu enquanto permaneceu nessa escola. Cícero não negava a existência da verdade, mas sim a possibilidade de discerni-la:

\begin{abstract}
Não somos daqueles a quem nada pareça ser verdadeiro, mas sustentamos que a verdade e a falsidade andam associadas e se mesclam; nelas não há nenhum sinal para que possamos discerni-las e dar-lhes assentimento, de onde resulta que o sábio deve reger sua vida segundo a probabilidade ${ }^{3}$.
\end{abstract}

O Contra Academicos é composto por três livros. Em linhas gerais o diálogo se estrutura da seguinte forma:

No primeiro livro a discussão sobre a verdade coloca-se no plano da felicidade; esta, em uma de suas feições, é definida como a vida vivida conforme o que o ser humano tem de melhor, isto é, a razão. Para sermos felizes precisamos encontrar a verdade ou basta procurá-la? Entre os elementos da solução a ser apresentada é necessário ressaltar no livro I a intervenção da sabedoria. Discutem-se algumas noções da sabedoria, como a da recta via vitae (13-150) e a de Cícero: rerum bumanarum divinarumque scientia (1617).

No segundo livro, o autor dirige-se inicialmente a Romaniano (pai de Licêncio, compatriota e benfeitor de Agostinho), exortando-o a dedicar-se à

\footnotetext{
1 Ver, por exemplo, Contra Academicos I, III, 7; II, XI, 26; III, XIX, 45.

2 Cf. BOYER, C., L'Idée de Vérité dans la Philosophie de Saint Augustin. Paris: Beauchesne et Ses Fils, 1940, p.27.

3 Cicero, Da Natureza dos Deuses, I, 5. Texto traduzido pela autora do espanhol e latim conforme a edição San Agustin, Contra Academicos. Madrid: BAC, 1971, p.5 (Introduccion): "Non sumus ii, quibus nihil verum esse videatur, sed ii qui omnibus veris falsa quaedam adiuncta esse dicamus tanta similitudine, ut in iis nulla insit certa iudicandi et assentiendi nota, ex quo existit illud, multa esse probabilia, quibus sapientis vita regatur" (De natura deorum).
} 
filosofia; depois expõe o ponto de vista dos filósofos acadêmicos, os quais, sustentando ser a verdade inacessível ao ser humano, pretendem que se possa e deva seguir o provável ou o verossímil. Expõe algumas incongruências desse modo de pensar.

O terceiro livro é em grande parte um discurso contínuo, onde Agostinho desenvolve sua crítica à concepção dos acadêmicos. Quer provar, aí, que o sábio necessariamente conhece algo de certo, isto é, a sabedoria. Após debater a definição que o estóico Zenão dá à verdade, irá refutar duas asserções basilares dos acadêmicos: a de que "Nada se pode perceber" isto é, nada se pode compreender, e a de que "Em nada devemos assentir" (em outras palavras, nada se deve aprovar).

Esse é basicamente o perfil do diálogo e dos temas a serem desenvolvidos. Nele, Agostinho não utiliza o termo "céticos" (sceptici); ao refutar o pensamento probabilista refere-se a Cícero empregando seu nome pessoal; ou refere-se aos acadêmicos (academici) ${ }^{4}$. O próprio título do diálogo circunscreve o tema: trata-se de uma crítica dirigida ao pensamento dos acadêmicos, de modo que não é possível inferir que Agostinho associe os céticos, de modo geral, aos acadêmicos (o diálogo não se refere a todos céticos, mas aos acadêmicos $)^{5}$.

Visto que no pensamento antigo há várias posições filosóficas, com nuanças próprias, que vieram a ser consideradas céticas, faz-se necessário distingui-las. Avançando nessa direção, seria preciso estar atento à diferença fundamental entre a filosofia da Nova Academia e o pensamento de Pirro, considerado o iniciador do ceticismo ${ }^{6}$.

Para Sexto Empírico, cuja obra é do séc. II d. C e teria revitalizado o pirronismo, haveria uma distinção crucial entre a Academia de Carnéades e o ceticismo: aqueles afirmariam ser a verdade inapreensível, e estes a continuariam buscando ${ }^{7}$. Assim, os acadêmicos afirmariam ser impossível

4 Por exemplo: II. VII, 16: Audisti qui sint Academici tui? ("Ouviste o que são os teus Acadêmicos ?").

5 DUTTON, B. D. (Augustine, Academic Skepticism, and Zeno's definition. Augustiniana. Louvain, 2003, p.7) deixa isso bem claro: "As is well known, but often ignored, Ausgustine's concern with skepticism was not a concern over some generic form of skepticism, whatever that would be, but with the skeptical tradition that arose in Plato's Academy and that was transmitted to him through the writings of Cicero".

${ }^{6}$ Pirro de Élis teria vivido de 360 a. C a 270 a. C. Não tendo escrito nenhuma obra seu pensamento é conhecido pelos fragmentos deixados por seu discípulo Tímon de Flios (325-235 a. C). Importa ressaltar que 0 ceticismo de Pirro teria uma preocupação ética e um caráter essencialmente prático: busca-se um modo de experienciar a vida prática com moderação e tranquilidade por meio da ataraxia (cf. SOUZA FILHO, p.89). Pode-se dizer que Agostinho também faria parte dessa linhagem de filósofos (Sócrates; Pirro) para os quais a filosofia implica um modus vivendi, e não apenas uma doutrina, uma teoria. $O$ que estaria em jogo aqui é o telos do ser humano e a eudaimonia (vida feliz).

${ }^{7}$ Apud SOUZA FILHO, 1994, p.86: Hipotiposes Pirrônicas (I, 1). 
encontrar a verdade e os céticos, por assim dizer 'autênticos', continuariam a procurá-la.

Em suma, a uma visão mais rigorosa, os acadêmicos são filósofos acatalépticos $^{8}$, visto que para eles não é possível encontrar qualquer verdade; assim, apenas em sentido largo podem ser considerados céticos. Foi no entanto sob essa designação que passaram a ser identificados. Os pirrônicos, por sua vez, seriam céticos em sentido próprio: buscam a verdade que não descobriram ${ }^{9}$. O ceticismo suspensivo que Sexto considera o único a merecer esse nome seria o proveniente da filosofia de Pirro de Élis.

A Nova Academia, correspondendo à fase acataléptica da Academia de Platão, teria se iniciado com Arcesilau a partir de 270 a. C., abrangendo Carnéades (219-129 a. C) e Clitômaco (175-110 a. C). Com Filon de Larissa (110 a. C), paulatinamente a Academia abandonará o ceticismo. Conhecemos sua doutrina sobretudo a partir do diálogo Academica de Cícero (55 a. C).

Observa Souza Filho:

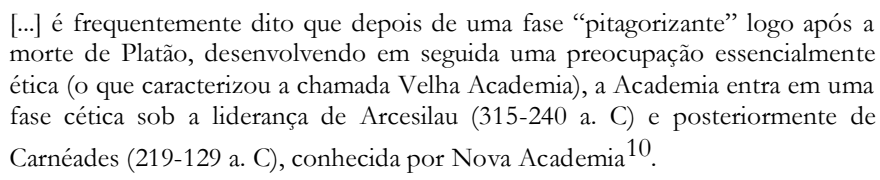

Esse autor problematiza a relação entre a Academia e o ceticismo. Como explicá-la, visto que Platão não foi um filósofo cético e a Academia foi um centro de difusão do platonismo? ${ }^{11}$ É de fato muito curioso concordamos com Souza Filho - que o termo 'acadêmico' tenha se tornado sinônimo de 'cético'... Ainda segundo esse autor, no Contra Academicos, que seria "uma das principais e mais influentes tentativas de refutação do ceticismo na Antiguidade", Agostinho identificaria "pura e simplesmente o Ceticismo com a Academia"12. Na verdade, como dissemos anteriormente, isso não acontece ${ }^{13}$.

${ }^{8}$ Cf. BOYER, 1940, p.29.

9 O termo grego skepsis significa literalmente "investigação", "indagação" (v. Souza Filho, p.87) em outras palavras, a afirmação de que a verdade seria inapreensivel já não caracterizaria mais uma posição cética.

10 SOUZA FILHO, 1994, p.85.

${ }^{11}$ Sobre a origem e significado da fase cética da Academia ver as reflexões de Souza Filho (1994, p.9094).

12 SOUZA FILHO, 1994, p.86.

13 DUTTON, B. D. (Augustine, Academic Skepticism, and Zeno's definition. Augustiniana. Louvain, 2003, p.7) deixa isso bem claro: "As is well known,but often ignored, Ausgustine's concern with skepticism was not a concern over some generic form of skepticism, whatever that would be, but with the 
Importa também tomar conhecimento da visão idiossincrática de Agostinho a respeito da Nova Academia. Em seu diálogo Contra Academicos, ele supõe que a posição acataléptica assumida pelos adeptos da Nova Academia seria empregada, a modo de estratégia, com o propósito de ocultar e preservar a verdadeira doutrina da Academia (o platonismo), para combater o materialismo, tanto o estoico quanto o epicurista ${ }^{14}$ (ambas escolas, apesar de suas diferenças, teriam como característica comum o materialismo, execrado pelos platônicos). Os Acadêmicos, na verdade, seriam platônicos ortodoxos e nunca o teriam deixado de ser. Essa interpretação encontra-se no final do livro III do Contra Academicos (III, XIX, 43) e também na Epístola 1, a Hermogeniano, onde Agostinho afirma que 'talvez seja mais uma hipótese do que uma certeza' (suspiciosus fortasse quam certius) ${ }^{15}$.

A despeito disso, se os novos acadêmicos teriam ou não uma doutrina secreta (o platonismo), importa acentuar que a filosofia da Nova Academia deve ser compreendida sobretudo a partir de sua oposição à filosofia estóica: os estóicos seriam os principais adversários dos acadêmicos, e era sua epistemologia empirista e materialista que estava em questão.

Ampliando um pouco mais nossa perspectiva, pode-se dizer que o pano de fundo do Contra Academicos nos situa no horizonte das seguintes correntes: a filosofia dos acatalépticos e o materialismo, tanto estóico quanto epicurista.

Em suma, trata-se principalmente de uma dupla discussão que está por trás do diálogo: a oposição de Agostinho aos acadêmicos, que, por sua vez, estaria ancorada na oposição dos acadêmicos aos estóicos. De modo que o problema de Agostinho será não apenas o de suplantar os acadêmicos, mas fazê-lo sem afirmar o materialismo estoico (e muito menos o epicurista). Seria trágico derrotar o ceticismo dos acadêmicos ao preço da afirmação do empirismo estóico $[. . .]^{16}$.

\section{Breve apresentação dos livros}

skeptical tradition that arose in Plato's Academy and that was transmitted to him through the writings of Cicero".

14 Cf. DUTTON (2003, p.7 e nota 1): "While these early writings depict the skeptical practice of the Academics as being almost exclusively directed against the Stoics, years later, in his Letter to Dioscorus (Ep. 118), he identifies the Epicureans as a target as well". Ver por exemplo: Contra Academicos III, XVI, 38.

15 V. Epístola 1. Madrid: BAC, 1986.

${ }^{16}$ Cf. DUTTON, 2003, p.8. 
Percorreremos agora um pouco mais detidamente cada um dos livros do diálogo, tendo em vista não uma discussão exaustiva de obra tão debatida ${ }^{17}$, mas apenas acentuando, na linha do que temos dito, elementos que mais nos chamam a atenção. Se até aqui nosso olhar foi externo à obra, agora procuramos analisá-la a partir de seu interior.

\section{LIVRO I}

Definir se o Contra Academicos foi escrito com o propósito de refutar o ceticismo epistemologicamente, ou se Agostinho tencionava enfatizar uma crítica ética aos acadêmicos, não é nossa primeira preocupação. Agostinho de fato propõe um argumento epistemológico de refutação aos 'céticos'? $\mathrm{Ou}$ simplesmente apela à sensibilidade ética de cada um? Tanto a crítica epistemológica do ceticismo quanto a crítica ética são amplamente discutidas pelos comentadores. Mas, antes de mais nada, está claro que esse diálogo é uma contribuição cristã à discussão das antigas escolas filosóficas sobre o telos e a eudaimonia ${ }^{18}$.

Visto que os argumentos do primeiro livro paulatinamente nos introduzem ao pensamento acadêmico, e estão associados principalmente à definição da felicidade, será preciso refletir sobre a relação entre a discussão da felicidade e o ceticismo acadêmico.

No que consistiria a vida feliz? Em continuação ao debate de um tema comum - o da felicidade, na esteira do ceticismo, estoicismo e epicurismo - propõe-se uma ruptura, que é a via cristã. Se a relação entre auctoritas e ratio se faz presente no Contra Academicos ${ }^{19}$, é preciso mostrar em que medida essa relação apelaria à irracionalidade, e em que medida a ratio pode e deve conduzir à beata vita, ao acesso à verdade e ao conhecimento.

Muitos comentadores concentram-se no terceiro livro, onde estariam os possíveis argumentos epistemológicos e éticos de refutação aos acadêmicos, e a maioria ignora os livros I e II. Mas, é preciso evitar uma falsa ideia do diálogo. Enquanto a justaposição da felicidade e do ceticismo pode parecer surpreendente $^{20}$, não surpreende aqueles familiarizados com o ceticismo antigo e seu objetivo (partilhado com as outras correntes do pensamento helênico) de justamente precaver-se contra a infelicidade. O diálogo Contra Academicos também não é um mero exercício de discussão vã e retórica: é a

17 Para uma análise detalhada do diálogo, ver por exemplo, Boyer (1940).

18 Cf. HOLTE,1965, p.76.

19 A esse respeito ver o livro III, XIX, 43.

20 No ceticismo moderno a questão da eudamonia perde importância (como, por exemplo, em Descartes e Montaigne). 
própria vida pessoal que está em jogo ${ }^{21}$.

Se a Nova Academia queria impedir os indivíduos de serem conduzidos ao materialismo estóico, por outro lado Agostinho compreendia o ensinamento dos acadêmicos como um empecilho para se alcançar o conhecimento e uma vida ética. Longe de não acreditar em nada (o que nos faria supor a suspensão de julgamento), os acadêmicos cultivariam uma crença perigosa.

Opondo-se aos acadêmicos que oferecem a via acataléptica como um meio à felicidade, Agostinho dirá que a beata vita é alcançada não apenas pela busca da verdade, mas somente quando esta é encontrada. Seriam poucos os que compreendem que a verdade pode ser encontrada, e é isso que faz com que a popularidade do ceticismo aumente. Haveria algumas principais causas que levariam as pessoas a não a procurarem: o fato de estarem com uma mente entorpecida (certa apatia dos espíritos); a desesperança de encontrá-la porque não é fácil; ou porque pensam já tê-la encontrado 22 .

Assim, Agostinho reconhece o desejo de verdade como uma legítima razão para se opor aos acadêmicos, e ao seu ver, o objetivo do ceticismo será pulverizar essa paixão pela verdade ao afirmar que ela não pode ser encontrada, o que só poderia conduzir à infelicidade.

Em algumas passagens do livro I encontra-se a noção de alma (animus), ou razão, como divina (a razão, nossa porção divina: faculdade divina; I, IV, 11). Mas se a alma humana, mortal, tem algo de divino (I, 1, 1 “ "...] divinum animum mortalibus); no entanto, isso não é garantia de felicidade. Esse 'não sei quê divino' (I, 1, 3) pode estar em um sono letárgico.

Salvo engano, em obras da maturidade (por exemplo em De Trinitate) não aparecem mais expressões semelhantes às citadas, que talvez pudessem conduzir a más interpretações (ao panteísmo, por exemplo). Se a alma (a razão ou espírito) possui algo de divino, é simplesmente por analogia a um Deus transcendente. Essa divinização, a ser admitida, no cristianismo possui um sentido muito preciso 23 .

Mais à frente no capítulo I, há outra expressão muito interessante, que a meu ver sintetiza o esforço de Agostinho presente em todo o diálogo:

21 V. Contra Academicos II, IX, 22.

22 Contra Academicos II, I, 1: "[...] sive ingeniorum quodam stupore, vel socordia vel tarditate torpentium, sive desperatione inveniend...; sive etiam qui error omnium populorum est, falsa opinione inventae a se veritatis, nec diligenter homines quaerunt, si qui quaerunt, et a quaerendi voluntate avertuntur".

23 Concernente a esse tema ver: Reta, J. O. De la iluminación a la deificación del alma según san Agustín. Madrid: Augustinus,1995, p.225-245. 
inteligir, desvelar algo sobre a verdade, que remete a um "Deus verdadeiro e secretíssimo": "Ela [a filosofia] promete demonstrar-nos claramente o Deus verdadeiro e secretíssimo, e pouco a pouco no-lo entremostra, como por entre nuvens lúcidas"24.

Deus silente e oculto? Por que 'secretíssimo' e por que a verdade se ocultaria aos sentidos, não estando ao seu alcance ${ }^{25}$. Podemos ler em seguida:

Não julgas, talvez, que os astros, que diariamente contemplamos, sejam alguma coisa grande, comparados com o verdadeiro e secretíssimo Deus a quem raramente a inteligência e nunca os sentidos alcançam ${ }^{26}$.

A estratégia de Agostinho ao combater os acadêmicos e o materialismo estóico mostra-se logo de início e se acentuará cada vez mais ao longo dos livros seguintes.

Após a dedicatória a Romaniano (capítulo I), Agostinho inicia os debates com a seguinte pergunta: - "Duvidais de que precisamos conhecer a verdade?"27. A verdade, como a sabedoria, liga-se à tranquilidade da alma ${ }^{28}$. Tema caro aos antigos; podemos salientar aqui também a discussão, proveniente da Antiguidade, sobre o cuidado e a transformação de si. Não se trata de discutir por puro prazer $[. . .]^{29}$.

De que todos desejam ser felizes ninguém discorda, mas, avançando no diálogo, Trigécio acrescenta que, se podemos ser felizes sem alcançar a verdade, ela será dispensável, e inútil sua busca. Então Agostinho intervém, questionando: "Como assim? Pensais que podemos ser felizes sem ter achado a verdade?" Licêncio, que aí figura como porta-voz da Nova Academia,

24 "Ipsa verissimum et secretissimum Deum perspicue se demonstraturam promittit, et iam iamque quasi per lucidas nubes ostentare dignatur" (I, 1, 3).

25 A intelecção da verdade também nos é vedada pelo limite de idade: "Licêncio - [...] porque nem desde que existe, por defeito da idade, pode logo o homem procurar a verdade"(quia non ex quo tempore incipit esse homo, eo iam potest, aetate impediente, verum quaerere; I, IV, 12).

26 "Nisi forte existimas sidera, quae quotidie contemplamur, magnum quiddam esse in comparatione verissimi et secretissimi Dei, quem raro fortasse intellectus, sensus autem nullus atingit" (I, VIII, 22).

27 "Numquidnam dubitatis, inquam, verum nos scire oportere?".

28 Sobre o tema da alma tranquila, ver também (1, IV, 11): "Licêncio - [...] Na verdade, vivemos de alma tranquila, livre de toda mácula do corpo, afastados do fogo do desejo, refletindo quanto ao homem é dado; isto é, vivendo segundo aquela divina faculdade, que, segundo a nossa definição de ontem, constitui a vida feliz". "Viximus enim magna mentis tranquillitate, ab omni corporis labe animum vindicantes, et a cupiditatum facibus longissime remoti, dantes, quantum homini licet, operam rationi; hoc est, secundum illam divinam partem animi viventes, quam beatam vitam esse hesterna inter nos definitione convenit: atqui, ut opinor, nihil invenimus, sed tantummodo quaesivimus veritatem".

29 Agostinho dirá em outra obra: "Portanto, antes de sua descoberta elas [as verdades] existiam nelas mesmas e, quando as descobrimos, elas nos renovam. "Ergo ante quam inveniantur, in se manent et cum inveniuntur, nos innovant" (De vera religione, cap. XXXIX, 73). 
introduz o tema central que desencadeia a discussão dos três livros: “Talvez seja a mesma coisa viver feliz e viver na busca da verdade... os nossos maiores, que temos por sábios e felizes, viveram bem e felizmente, só porque procuravam a felicidade" 30 .

O problema está dado: para uns a simples investigação da verdade conduz à vida feliz; Cícero, como se mostrará adiante, teria insistido na impossibilidade do conhecimento e em que só restava ao sábio a investigação aturada (I, III, 7); para outros só a posse da verdade garante a felicidade.

Será apresentada uma definição da vida feliz: ela implica viver segundo nossa porção divina, a razão (I, II, V; I, IV, 2). Nessas passagens se estabelece uma ligação da felicidade com a noção de sábio e de sabedoria. Licêncio interroga Trigécio perguntando por que não poderia ser feliz quem apenas procura a verdade, embora não a encontre (I, III, 7). Segundo Trigécio, só é feliz o sábio perfeito, e aquele que procura não é perfeito, pois não teria atingido seu próprio fim, e nem alcançado o que ardentemente deseja.

Licêncio continuará opondo-se a Trigécio, insistindo em que procurar a verdade é atingir o objetivo inultrapassável do ser humano... Em dado momento entrará em discussão a definição da sabedoria (I, V, 13). A primeira definição proposta por Trigécio - a sabedoria é o reto caminho da vida (recta via vitae I, V, 13) - é considerada, por Licêncio, ridícula. Trigécio, então, a redefine como o caminho direto para a verdade $(I, V, 14)$ e essa definição também é contestada. Trigécio pede o socorro de Agostinho, que finalmente apresentará a definição de Cícero: a sabedoria é a ciência das coisas divinas e humanas (rerum bumanarum divinarumque scientia I, VI, 16). Licêncio, por sua vez, também a contestará.

Adiante Trigécio delimitará um pouco mais a última definição, acrescentando: "sabedoria é a ciência das coisas divinas e humanas necessárias à vida feliz" (I, VIII, 23). Licêncio a rejeitará novamente, acrescentando uma retificação que parece remeter a discussão ao seu ponto inicial... ("sapiência me parece consistir não só no conhecimento das coisas divinas e humanas concernentes à vida feliz mas também na sua busca diligente"). A partir daí nada se acrescentará de relevante; o debate, praticamente tendo se esgotado, irá se mostrar redundante ${ }^{31}$.

Próximo ao fim desse primeiro livro é apresentado um resumo das

${ }^{30}$ I, II, 5-6.

31 Em suas observações finais sobre esse primeiro livro diz Agostinho: " [...] encerremos esta conversação cujo prolongamento julgo inútil. $\mathrm{O}$ assunto está discutido e poderia ter-se concluído em poucas palavras, se eu não tivesse grande empenho de exercitar-vos e pôr à prova os vossos nervos e aplicação" (I, IX, 25). 
posições dos debatedores (I, IX, 24). A definição de sabedoria de Licêncio é desdobrada, adquirindo a seguinte forma: "a sabedoria humana é aquela busca da verdade pela qual, devido à tranquilidade da alma, se atinge a vida feliz".

Agostinho conclui afirmando que se quisermos ser felizes, quer isso dependa do achado quer simplesmente da busca da verdade, uma coisa é certa, que a verdade deve ser procurada (I, IX, 25). Doravante, Licêncio e Alípio defenderão a posição dos acadêmicos, citados por Agostinho como réus.

\section{LIVRO II}

No livro anterior pretendeu-se enfatizar a questão da eudaimonia e da sabedoria associada à importância da vida pessoal; agora esta será relacionada à verdade e à questão do conhecimento. Nos fixaremos também na discussão sobre a noção de verdade, proposta por Zenão ${ }^{32}$, que é introduzida nesse livro, e na exposição da doutrina dos acadêmicos.

Quanto ao encontro da verdade apresenta-se um primeiro critério de certeza fundado no campo do inteligível, conforme exemplo das certezas matemáticas:

[...] não julgueis saber alguma coisa, a não ser como sabeis que a soma de um, dois, três e quatro é dez. Mas não penseis também que é impossível achar a verdade em filosofia. Acreditai-me, ou antes, naquele que disse: "Procurai e achareis". Não se deve desesperar de um conhecimento mais evidente do que o daqueles números (II, III, 9) ${ }^{33}$.

No cap. V-11, Agostinho faz um apanhado das ideias dos acadêmicos - importa enfatizar que esse é o modo como ele interpreta a sua doutrina -, que por sua vez, tomando a definição de verdade proposta por Zenão, irão fundamentar uma crítica aos estóicos e elaborar seu pensamento.

Os acadêmicos afirmam a impossibilidade do conhecimento. Não obstante, para eles, ainda assim é possível ser sábio (basta apenas que se busque a verdade). A partir daí inferem que o sábio não deve dar assentimento a coisa alguma. Tentando demonstrar que tudo é incerto, extraem a ideia da inacessibilidade da verdade, baseados na definição de Zenão.

Essa definição será o ponto de partida para todos os desenvolvimentos ulteriores. Ela será crucial tanto para a crítica que os

32 Zenão de Cítio (334 a. C a 262 a. C) foi o fundador do estoicismo e teria lecionado em Atenas por volta do ano 300 a. C.

33 "....] cavete ne quid vos nosse arbitremini, nisi quod ita didiceritis, saltem ut nostis, unum, duo, tria, quatuor simul collecta in summa fieri decem. Sed item cavete ne vos philosophia veritatem aut non cognituros, aut nullo modo ita posse cognosci arbitremini. Nam mihi vel potius illi credite qui ait: Quaerite et invenietis (Mt 7, 7), nec cognitionem desperandam esse, et manifestiorem futuram, quam sunt illi numeri". 
acadêmicos farão ao estoicismo, quanto para a crítica de Agostinho aos acadêmicos.

Conforme a explicação de Agostinho, para Zenão "só pode ser verdadeira uma impressão na alma, quando não pudesse existir se aquilo do que provém não existisse" 34 . Em poucas palavras, seria o mesmo dizer que "o verdadeiro só pode ser reconhecido por sinais que o falso não possa ter".

Enfim, se o verdadeiro só pode ser reconhecido por sinais que o falso não possa ter, os acadêmicos dirão que esses sinais não são encontráveis. Exemplo disso seria a divergência dos filósofos (por que tantas e diversas doutrinas inconciliáveis?); os erros a que somos induzidos por conta dos sentidos; os sonhos (como distinguir a vigília?); os delírios, etc..

Neste ponto do diálogo passamos a um outro plano. Se no livro I o que parece estar em discussão é a noção de uma verdade metafísica, aqui 'o verdadeiro’ (verum) parece referir-se às verdades científicas (já não estaríamos mais no domínio da metafísica e sim da física). A crítica dos acadêmicos englobaria a impossibilidade do conhecimento em dois domínios: tanto no campo da metafísica, quanto da física. Em suma, a verdade seria completamente inacessível (Hume e Kant teriam em quem se inspirar).

Avancemos na exposição da doutrina dos acadêmicos feita por Agostinho. Levando em conta a ideia de Zenão de que a opinião é algo vil, e visto que não podemos discernir o verdadeiro do falso, conclui-se que nada se pode apreender (conhecer) e que, portanto, o sábio não deve aprovar coisa alguma $^{35}$.

Desse modo os acadêmicos atrairiam para si grande hostilidade, visto que "parece que nada deve fazer quem nada aprova" (II, V, 12). Quanta preguiça, quanta inércia... é assim que o próprio Agostinho se auto-analisa em sua fase cética.

Afirmavam também os acadêmicos, como conclusão provável, ou também denominada verossímil, que o sábio cumpriria seus deveres se tivesse alguma norma orientadora: a suspensão de julgamento (assentimento) já seria para ele uma grande atividade. Se para os acadêmicos a existência da verdade é certa, por outro lado pode-se dizer que a verdade estaria oculta ou confusa. Assim, também eram tidos por inimigos do conhecimento humano ${ }^{36}$.

A seguir há, no diálogo, uma aparente digressão: Alípio pede que se

\footnotetext{
34 "[...] id verum percipi posse, quod ita esset animo impressum ex eo unde esset, ut esse non posset ex eo unde non esset. Quod brevius planiusque sic dicitur, his signis verum posse comprehendi, quae signa non potest habere quod falsum est". (II, V, 11).

35 "[...] ut si nihil percipi posset, et esset opinatio turpissima, nihil unquam sapiens approbaret".

${ }^{36}$ Conferir em: II, X, 24.
} 
exponha a diferença entre a Nova e a Velha Academia (II, V, 13). Explica-se que a separação entre a Nova e a Velha Academia diz respeito mais a uma oposicão aos estoicos do que à doutrina antiga, e o motivo introduzido será uma das chaves de toda a discussão: a impossibilidade da percepção como conhecimento ${ }^{37}$.

De modo que surge a pergunta, inicialmente subentendida e depois abordada mais claramente por Agostinho no livro $\mathrm{III}^{38}$ : o conhecimento se reduz à percepção sensível e ao sensível, tal como propõem os estóicos? A razão, ao buscar seu conteúdo no sensível, desilude-se [...].

No capítulo seguinte (VII) é retomado o debate a respeito dos acadêmicos e Agostinho, logo de início, não deixará de divertir o leitor com suas armas retóricas. Será criticada a ideia de probabilidade - associada à verossimilhança - por meio de uma comparação de parentesco (v. II, VII, 16).

Pergunta-se a Licêncio se os acadêmicos lhe agradam. Respondendo que sim, dispara Agostinho se lhe parece que os acadêmicos falam a verdade... Percebendo a emboscada por causa do sorriso de Alípio, ele hesita, e finalmente responde não saber se falam a verdade, mas que se trata de algo provável. Ora, o provável, para os acadêmicos, é também denominado verossímil ${ }^{39}$.

Agostinho argumenta: como algo pode ser verossímil, isto é semelhante à verdade, se a verdade não é conhecida? Dirigindo-se a Licêncio pergunta-lhe se alguém, que não conheça o pai dele, lhe afirmar que seu irmão se parece com o pai, não parecerá um imbecil ou louco. Dirá adiante que são ridículos os acadêmicos que pretendem seguir o verossímil ignorando o verdadeiro (II, VII, 18) ${ }^{40}$. Em outras palavras: "tais são os que dizem: não conhecemos o verdadeiro; mas o que vemos é semelhante ao que desconhecemos" ${ }^{\prime 4}$.

À frente reitera-se observação colocada anteriormente: o diálogo não

37 II, VI, 14: "Nam de non percipiendo, quamvis nullis conflictationibus agitata, incolens tamen etiam veterum Academicorum mentes sententia non impudenter existimata est".

38 III, X, 26: "Alguns há que das impressões recebiddas dos sentidos pelo espirito afirmam poder vir a opinião, não a ciência. Esta julgam-na contida na inteligência, fora dos sentidos. Talvez seja destes o sábio que procuramos." ("Sunt enim qui ista omnia, quae corporis sensu accipit animus, opinionem posse gignere confitentur, scientiam vero negant. Quam tamen volunt intellegentia contineri, remotamque a sensibus in mente vivere. Et forte in eorum numero est sapiens ille quem quaerimus").

39 "Probabile, inquam, scisne ab ipsis etiam verisimile nominari?"

40 "Ipsa res clamat similiter ridendos esse Academicos tuos, qui se in vita veri similitudinem sequi dicunt, cum ipsum verum quod sit, ignorent".

41 "Quia tales, inquam, sunt, qui dicunt: Verum quidem non novimus; sed hoc quod videmus, eius quod non novimus simile est" (II, VIII, 20). 
se trava pelo prazer de discutir (o que seria interessante para um mestre em retórica tal como Agostinho o fôra), mas Agostinho será veemente: "Trata-se da nossa vida, dos nossos costumes, da nossa alma que espera vencer todos os enganos, conhecer a verdade" 42 .

Do livro II, no que concerne à nossa discussão, isso é o principal. Trata-se daqui para a frente - como dirão Alípio e Agostinho no final do segundo livro - "de saber se a verdade pode descobrir-se" 43 , "de averiguar se pelos argumentos dos acadêmicos é provável que nada é possível saber, e em nada é lícito assentir" ou de demonstrar "que é muito mais provável que o sábio alcance a verdade, e que nem sempre o assentimento deve suspenderse"44. Passemos então ao terceiro e último livro.

\section{LIVRO III}

Muitos argumentos acadêmicos seriam ininteligíveis fora do contexto estóico para o qual haviam sido elaborados. Agostinho discute exatamente isso: a negação acadêmica da possibilidade do conhecimento dirigida principalmente contra a epistemologia estóica empirista.

O debate entre os acadêmicos e os estóicos se estabelecerá, em grande parte, em torno dessa questão: se há uma classe de impressões que podem gerar conhecimento. Dizendo de outro modo, a percepção sensível poderia gerar conhecimento? O conjunto de condições estabelecido por Zenão seria satisfatório? ${ }^{45}$. Agostinho compreende isso e desenvolve o tema inspirado no neoplatonismo. Não se deve esquecer, entretanto, que essa abordagem seria parte de uma resposta mais ampla apresentada por Agostinho aos acadêmicos.

Se é dado por certo, como fazem os acadêmicos, que todo conhecimento provém dos sentidos e é do sensível, a consequência é que o conhecimento certo parecerá impossível. Definir a relação do sensível e da razão será importante para a reflexão sobre o acesso à verdade.

Feitas essas observações, passemos ao livro III, que inicia com a afirmação de que a busca da verdade com todo empenho não é algo leve nem supérfluo, mas importantíssimo e necessário. Agostinho sustenta não apenas

42 "De vita nostra, de moribus, de animo res agitur; qui se superaturum inimicitias omnium fallaciarum, et veritate comprehensa" (II, IX, 22).

43 "in eam quaestionem, qui utrum inveniri verum possit quaeritur" (II, XII, 28).

44 Quaeritur ergo inter nos, utrum illorum argumentis probabile sit nihil percipi posse, ac nulli rei esse assentiendum... si autem demonstrare potuero multo esse probabilius, et posse ad veritatem pervenire sapientem, et assensionem non semper esse cohibendam" (II, XIII, 29).

45 Cf. DUTTON, 2003, p.8. 
que é possível conhecer a verdade, mas também que não podemos não conhecê-la ${ }^{46}$; em outras palavras, para agir é preciso discerni-la.

Os capítulos iniciais retomam a discussão da sabedoria. Faz-se também uma diferenciação entre o sábio e o filósofo; um conhece a sabedoria e o outro pretende conhecê-la (III, III, 5). Agostinho procura mostrar que o sábio conhece a sabedoria. Se ninguém pode conhecer o falso, então o sábio conhece a verdade. "Aquele a quem parece que o sábio conhece a sapiência não pode, claro está, parecer que o sábio nada sabe. A não ser que diga que a sapiência nada é" ${ }^{\prime 4}$.

Os acadêmicos teriam pensado que é possível ser sábio, no entanto disseram que não pode haver ciência. Isso seria o mesmo que afirmar que o sábio nada sabe. Para concluir o raciocínio de Agostinho a esse respeito: é irracional sustentar ao mesmo tempo a possibilidade da sabedoria e a impossibilidade da ciência. Se o filósofo busca a sabedoria, como o nome indica e como a experiência o mostra, retirar-lhe a esperança de encontrá-la é retirar-lhe toda razão de filosofar; dar-lhe essa esperança, é retirá-lo da Nova Academia.

Apontando as contradições dos acadêmicos, Agostinho recorre então à definição da verdade de Zenão, tal como se vê no cap. IX e seguintes. Ele o faz, em linhas gerais, principalmente em 3 etapas:

Primeiro, emprega a definição em uma série de dilemas que apresenta aos acadêmicos. Segundo, argumenta que os acadêmicos devem conceder que a definição [de Zenão] é verdadeira e pode ser reconhecida como tal. Terceiro, enumera um conjunto de verdades que afirma satisfazerem as condições da definição de Zenão ${ }^{48}$.

Ora, se os acadêmicos partem da definição de Zenão, aceitando-a e afirmando que nada se pode saber, partem já da afirmação de uma verdade ${ }^{49}$. Trata-se de um pensamento um tanto quanto confuso; afirmarão então os acadêmicos que a definição de Zenão é uma probabilidade, ideia também contraditória para Agostinho.

Em seguida discutem-se duas ideias que os acadêmicos formulam

46 Cf. BOYER, 1940, p.30.

47 "Cui ergo videtur sapientem, scire sapientiam, non utique videtur nihil scire sapientem. Hoc enim contendi non potest, nisi quisquam dicere audeat, nihil esse sapientiam" (III, III, 6).

48 DUTTON: "First, he employs the definition in a series of dilemmas that he poses to the Academics. Second, he argues that the Academics must concede that the definiton is true and can be known to be so. Third, he enumerates a set of truths that he claims satisft the conditions of the definition" $(2003,17)$.

49 "Negam os Acadêmicos que possa saber-se alguma coisa. De onde o concluis, homens diligentíssimos e doutíssimos? "Convence-nos, dizem, a definição de Zenão. "Por quê?", pergunto. Se é verdadeira, alguma coisa sabe quem a sabe; se falsa, não deve abalar espíritos fortes" (III, IX, 18). 
com base na definição de Zenão: se não é possível encontrar nada que não possua sinais do falso, logo, "Nada pode perceber-se" e "Em nada devemos assentir" 50 . Novamente, o que estaria em questão nessas sentenças é a percepção sensível (percipere) e seu alcance, visão à qual Agostinho se opõe.

Adiante serão introduzidos os argumentos voltados à intuição intelectual (III, X, 25). Surgem aqui alguns princípios a priori, pouco a pouco enumerados. Eles provêm da matemática, da dialética, da psicologia (estes serão claramente desenvolvidos em obras posteriores).

Nesse percurso, é interessante notar o papel atribuído aos sentidos, que não devem ser desprezados (“... muito se poderia dizer em favor dos sentidos, que não vemos constestado pelos Acadêmicos") 51 . Quando os sentidos falam, dizem a verdade?

Os sentidos relatam o que percebem, não exatamente o que as coisas são; cabe ao intelecto discernir. Agostinho diz se alinhar com aqueles para os quais a ciência estaria contida na inteligência, fora dos sentidos: das impressões recebidas dos sentidos pelo espírito viria a opinião, e não a ciência ${ }^{52}$. O texto buscará, então, deixar mais claro o âmbito das certezas inabaláveis: "[...] penso que está na mente o sumo bem do homem" 53 .

Em seguida expõe-se uma série de verdades provenientes da dialética:

Se há quatro elementos no mundo, não são cinco; se o sol é um, não são dois. A mesma alma não pode ser mortal e imortal. O homem não pode ser simultaneamente feliz e infeliz. Aqui não pode ao mesmo tempo luzir o sol e ser noite. Neste momento ou dormimos ou estamos acordados. O que julgo ver ou é ou não é corpo. Estas e muitas outras coisas de longuíssima enumeração por ela aprendi que são verdadeiras em si, seja qual for o estado de nossos sentidos. Ela me ensinou que, aceito o antecedente nas proposições anteriores, o consequente é necessário $[\ldots]^{54}$.

Após isso será retomado o tema do sábio e da sabedoria, agora de modo conclusivo ("ou o acadêmico não é sábio ou o sábio assentirá em alguma coisa" III, XIII, 31) para se chegar à questão dos atos humanos: "quem

50 "Nihil posse percipi" e "Nulli rei debere assentiri" (III, X, 22).

51 "Quamquam etiam pro ipsis sensibus multa posse dici video, quae ab Academicis reprehensa non invenimus" (III, X, 25).

52 III, X, 26.

53 "[...] in mente arbitror esse summum hominis bonum" (III, XI, 27).

54 "Si quatuor in mundo elementa sunt, non sunt quinque. Si sol unus est, non sunt duo. Non potest una anima et mori et esse immortalis. Non potest homo simul et beatus, et miser esse. Non hic et sol lucet, et nox est. Aut vigilamus nunc, aut dormimus. Aut corpus est, quod mihi videre videor, aut non est corpus. Haec et alia multa, quae commemorare longissimum est, per istam didici vera esse, quoquo modo sese habeant sensus nostri, in se ipsa vera. Docuit me, si cuius eorum quae per connexionem modo proposui pars antecedens assumpta fuerit, trahere necessario id qod annexum est"(III, XII, 29). 
nada aprova nada faz" (III, XIV, 33). De modo enfático Agostinho critica o probabilismo: "Quem não rirá disto? Eles próprios dizem que na prática seguem o provável, e procuram a verdade, embora julguem improvável achá-la. Admirável monstruosidade" 55 .

A probabilidade poderia também funcionar como alibi a diversos crimes: homicídios, parricídios, adultério, etc ("Nada aprovei e portanto nada errei. Como não fazer o que pareceu provável ?") ${ }^{56}$.

Nos dois capítulos seguintes (XVI, XVII) Agostinho apresenta sua visão do que julga ser o pensamento dos acadêmicos. A doutrina da impossibilidade da ciência e o probabilismo dos acadêmicos seria apenas aparente, uma arma para combater o materialismo dos estoicos ${ }^{57}$, para quem diziam que Deus é fogo, a alma é mortal, e só existe o mundo sensível ${ }^{58}$.

Os acadêmicos, na verdade, seriam de fato platônicos, conforme dito anteriormente. Traça então Agostinho a história da Nova Academia e suas origens, remetendo a Platão e seu ensinamento de que haveria dois mundos:

[...] um, inteligível, domínio da verdade, outro sensível, que conhecemos pela vista e pelo tato. Aquele é verdadeiro, este verossímil e feito à imagem do primeiro. Do primeiro pode gerar-se a verdade límpida e serena na alma que se conhece ; do segundo, na alma dos estultos, não a ciência mas a opinião [... ${ }^{59}$.

Tem-se, assim, como que o coroamento de sua exposição anterior, à qual, finalmente, atribui um caráter cristão:

Tal o juízo que vim, conforme pude, a formar dos Acadêmicos. Se é falso, não importa; basta-me não crer que o homem não pode alcançar a verdade. Quem aos Acadêmicos dá esta opinião, ouça o próprio Cícero. Pois ele diz que ocultavam a sua doutrina e só a revelavam aos que com eles conviviam até a velhice. ...Ninguém ignora que só aprendemos pelo peso da autoridade e da razão. Para mim é certo que nunca me afastarei da autoridade de Cristo, que tenho por superior a todas. Quanto ao que exige raciocínio sutil, pois que desejo ardentemente não só crer mas compreender a verdade, confio poder encontrar

55 "Iam illud quis non ridet? Ipsi dicunt, nihil se in agendo sequi nisi probabile, et quaerunt magnopere veritatem, cum eis sit probabile non posse inveniri. O mirum monstrum!" (III, XV, 36).

56 "Nihil consensi, et ideo non erravi. Quomodo autem non facerem quod probabile visum est?"(III, XV, 36).

57 III, XVII, 41; III, XVII, 43.

58 III, XVI, 38.

59 "[...] unum intellegibilem, in quo ipsa veritas habitaret; istum autem sensibilem, quem manifestum est nos visu tactuque sentire. Itaque illum verum, hunc veri similem et ad illius imaginem factum. Et ideo de illo in ea, quae se cognosceret, anima velut expoliri et quasi serenari veritatem; de hoc autem in stultorum animis non scientiam, sed opinionem posse generari". 
entre os platônicos o que não repugne aos nossos mistérios ${ }^{60}$.

\section{Considerações finais}

Podemos dizer com Boyer ${ }^{61}$ que, cada vez que Agostinho se depara com o problema da certeza, parte dos argumentos desse diálogo da juventude. Assim, o Contra Academicos conteria o pensamento definitivo de Agostinho sobre o modo do conhecimento da verdade, e seria a principal fonte sobre esse tema. Isso já é o suficiente para justificar a atenção a esse primeiro diálogo agostiniano. Suas obras posteriores desenvolvem, muitas vezes com novas fórmulas, esses argumentos iniciais.

Uma vez que os acadêmicos suspeitam da percepção sensível e das ilusões a que somos conduzidos pelos sentidos, negando a possibilidade da ciência, Agostinho, por outro lado, diz que é possível apreendermos, mediante uma visão intelectual, realidades desvinculadas do tempo e do espaço. A sabedoria, a justiça, o bem moral, as leis dos números, os preceitos da dialética, são noções e leis (ou por assim dizer, princípios a priori tal como viriam a ser chamados posteriormente) que permaneceriam preservadas das críticas dos acadêmicos.

Se Agostinho buscava verdades indubitáveis, seria preciso um método para encontrá-las. Da solução dada a essa questão lhe parecia depender seu êxito. Acreditava que a verdade permanecia oculta unicamente por não dispormos de um método adequado para encontrá-la. Esse método, ele o localizou junto ao neoplatonismo. Isto é, a verdade não deve ser buscada no exterior, mas a partir da consciência e nela mesma: essa é uma das características marcantes de seu pensamento.

Em suma, a experiência interna teria absoluta primazia sobre a externa, e regula todo o processo de conhecimento. Agostinho sempre conservou a posição tomada em Cassicíaco; seu pensamento essencial já estava presente nos diálogos, isto é, a doutrina sobre a absoluta preeminência da certeza e da interioridade.

Os desenvolvimentos e formulações da preeminência da interioridade

60 Hoc mihi de Academicis interim probabiliter, ut potui, persuasi. Quod si falsum est, nihil ad me, cui satis est iam non arbitrari, non posse ab homine inveniri veritatem. Quisquis autem putat hoc sensisse Academicos, ipsum Ciceronem audiat. Ait enim illis morem fuisse occultandi sententiam suam, nec eam cuiquam nisi qui secum ad senectutem usque vixisset, aperire consuesse (Cicerone, Varro, fr. $35 \mathrm{t}$. A)....Nulli autem dubium est gemino pondere nos impelli ad discendum, auctoritatis atque rationis. Mihi ergo certum est nusquam prorsus a Christi auctoritate discedere: non enim reperio valentiorem. Quod autem subtilissima ratione persequendum est; ita enim iam sum affectus, ut quid sit verum, non credendo solum, sed etiam intellegendo apprehendere impatienter desiderem; apud Platonicos me interim quod sacris nostris non repugnet reperturum esse confido" (III, XIX, 43).

61 1940, p.24. 
- instrumentos de crítica à dúvida cética - podem ser acompanhados em obras posteriores, por exemplo, por meio dos desdobramentos dados ao cogito, onde o pensamento de Agostinho se depura.

Diz Boyer:

[...] entre as verdades que podemos propor aos acadêmicos para lhes fazer reconhecer uma visão intelectual, real e indiscutível, Agostinho escolhe, com uma preferência cada vez mais acentuada, o fato de nossa própria existência e de nosso próprio pensamento. No Contra Academicos esse argumento é pouco utilizado; é lançado apenas brevemente $[\ldots]^{62}$.

Mas no De libero arbitrio (diálogo concluído em 395) coloca-se claramente: a dúvida não pode atingir quem afirma sua própria existência, pois, para se enganar, é preciso ser (II, 3, 7).

Em De vera religione (escrito por volta de 389), também a dúvida revela-se fecunda: é por meio dela que o sujeito percebe-se pensante e existente: "Se você duvida da verdade dessas coisas, pense ao menos se você tem certeza de duvidar; e se está claro que você tem dúvida, examine de onde vem essa certeza"63.

O caminho para refutar os acadêmicos implicaria explicitar os princípios a priori e em nossa capacidade de ultrapassar as aparências:

[...] se você tem certeza da sua dúvida, procure de onde ela vem: não é de modo algum a luz do sol que você encontrará, mas a luz verdadeira que ilumina todo homem que veio ao mundo... Qualquer um que compreende que duvida, compreende uma coisa, e ele está certo dessa coisa que compreende. É de uma coisa verdadeira que ele está certo. Portanto, qualquer um que duvida da existência da verdade, possui nele uma coisa verdadeira da qual ele não duvida: ora, as coisas só são verdadeiras pela verdade. Portanto, não deve duvidar da verdade aquele que pode de algum modo duvidar. Aí onde vemos essas coisas, aí está a luz que não possui nenhuma dimensão de espaço nem tempo, nem imagem alguma dessas dimensões $[\ldots]^{64}$.

Assim, estão postas as bases para uma interpretação profundamente cristã do 'cogito' e da existência humana.

\section{BOYER, 1940, p.45.}

63 "Aut si non cernis quae dico, et an vera sint dubitas, cerne saltem utrum te de iis dubitare non dubites; et si certum est te esse dubitantem, quaere unde sit certum" (XXXIX, 73).

64 "....] si certum est te esse dubitantem, quaere unde sit certum: non illic tibi, non omnino solis huius lumen occurret, sed lumen verum quod illuminat omnem hominem venientem in hunc mundum... Omnis qui se dubitantem intellegit, verum intellegit, et de hac re quam intellegit certus est: de vero igitur certus est. Omnis ergo qui utrum sit veritas dubitat, in seipso habet verum unde non dubitet; nec ullum verum nisi veritate verum est. Non itaque oportet eum de veritate dubitare, qui potuit undecumque dubitare. Ubi videntur haec, ibi est lumen sine spatio locorum et temporum, et sine ullo spatiorum talium phantasmate" (De vera religione XXXIX, 73). 


\section{Referências}

AUGUSTINUS, A. Aurelii Augustini Opera. Turnholti: Brepols, Corpus Christianorum Series Latina (v. 27, 29, 50), 1970. . Contra Academicos. Madrid: BAC, 1971. . Contra os Académicos. Coimbra: Atlântida, 1957. . De Trinitate. Paris: Institut d'Études Augustiniennes, 1993. . A Verdadeira Religião. São Paulo: Paulinas, 1987. . Confissões. São Paulo: Abril Cultural, 1973.

BOYER, C. L'Idée de Vérité dans la Philosophie de Saint Augustin. Paris: Beauchesne et Les Fils, 1940.

CICERO. De natura deorum. Cambridge: Cambridge Univ. Press, 2009.

CURLEY, A. J., Augustine's Critique of Skepticism: a Study of Contra Academicos. New York/Washington, D. C: Peter Lang, 1997.

DUTTON, B. D. “Augustine, Academic Skepticism, and Zeno's definition”. In: Augustiniana, Louvain, 2003, p.7-30.

HOLTE, R. Béatitude et Sagesse. Paris: Études Augustiniennes,1962.

RETA, J. O. "De la iluminación a la deificación del alma según san Agustín". In: Augustinus. Madrid, 40, p.225-245, 1995.

SOUZA FILHO, D. M. “O ceticismo antigo: pirronismo e nova academia". In: Revista de Ciências Humanas. Florianópolis, v.11, n.15, p.85-95, 1994.

E-mail: marianapaolozzi1@gmail.com

Recebido: 26/03/2014

Aprovado: 21/05/2015 